\title{
ACute Myocardial Infarction AFTer Blunt Chest Trauma
}

\author{
Sivakumar Srinivasan, MD, Sandeep Anreddy, MD, and Paul Mather, MD
}

\section{Introduction}

Coronary artery injury rarely occurs after blunt chest wall trauma. It can, however, lead to extensive myocardial infarction. We report a rare case of acute anterolateral myocardial infarction in a young man after blunt chest trauma.

\section{Case Presentation}

A 30 year-old man was transferred to the emergency room after a motor vehicle accident. He was an unrestrained passenger in an ambulance and was ejected from the vehicle on impact resulting in multiple injuries including blunt chest trauma. Upon arrival to the emergency room his blood pressure was $118 / 69 \mathrm{mmHg}$ and pulse rate $95 / \mathrm{min}$. Initial physical examination revealed multiple large abrasions across bilateral anterior chest wall and normal cardiovascular, respiratory and abdominal examinations. Routine EKG showed Q wave and ST segment elevation throughout the precordial leads as well as leads I and aVL (Figure1).

The initial laboratory results including chemistry panels and blood counts were normal, however cardiac specific troponin was $152.40 \mathrm{ng} / \mathrm{mL}$. Urgent two-dimensional echocardiography showed apical, septal, and anterior wall akinesis with resultant severely depressed left ventricular function.

A diagnostic coronary angiogram revealed $100 \%$ occlusion of the proximal LAD distal to the origin of the first septal perforator. The lesion was associated with a moderate filling defect consistent with thrombus. Percutaneous coronary intervention was successfully performed for the lesion and the post-procedural angiogram showed excellent coronary flow without residual stenosis (Figures 2 and 3). Follow up cardiac specific troponin I on day 9 was $2.90 \mathrm{ng} / \mathrm{mL}$.

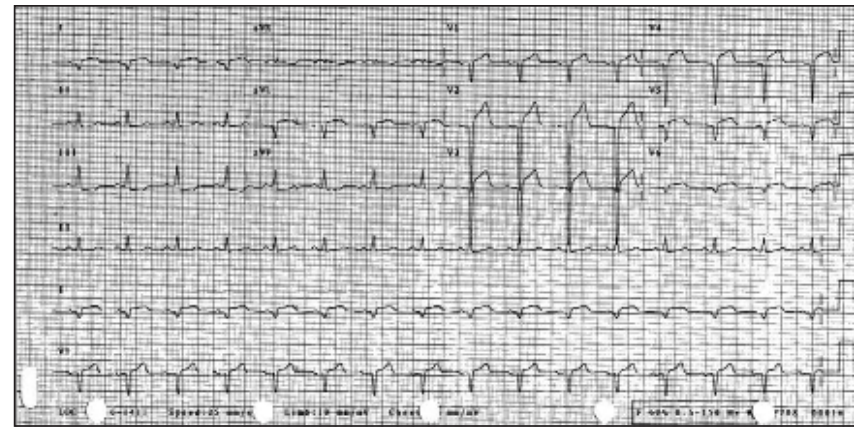

Figure 1.

\section{Discussion}

This case presents a rare complication of blunt chest trauma. To save myocardium from ischemic injury, prompt diagnosis is vital and routine EKG check should be performed in all the patients with chest trauma. Observations from case series suggest that the mechanism leading to myocardial infarction after blunt chest trauma is a shear force applied to the coronary artery with resultant intimal tearing. This injury precipitates platelet aggregation and intracoronary thrombosis. The higher incidence of left anterior descending artery involvement may be due to the proximity of this artery to the chest wall. Most trauma patients will not be candidates for thrombolytic therapy because of the high risk of bleeding from concomitant injuries. Given a skilled catheterization laboratory team, direct PTCA can be performed in seriously ill patients quickly and with outstanding results without the necessitate for thrombolytic agents.

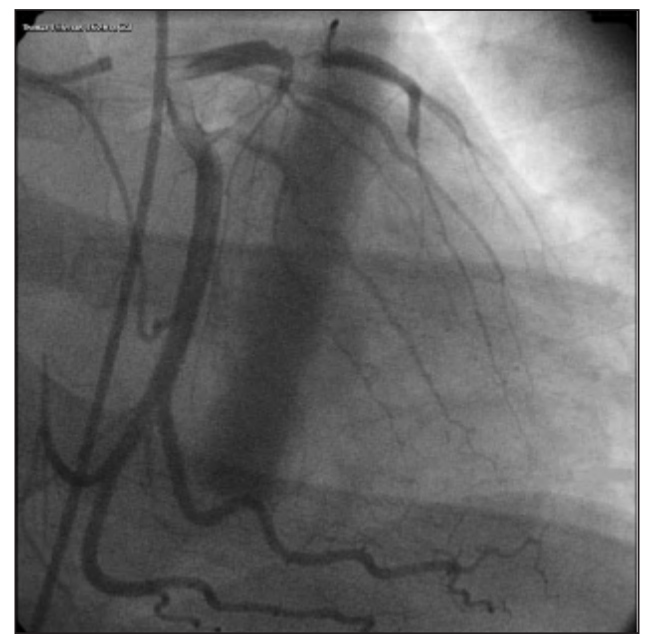

Figure 2.

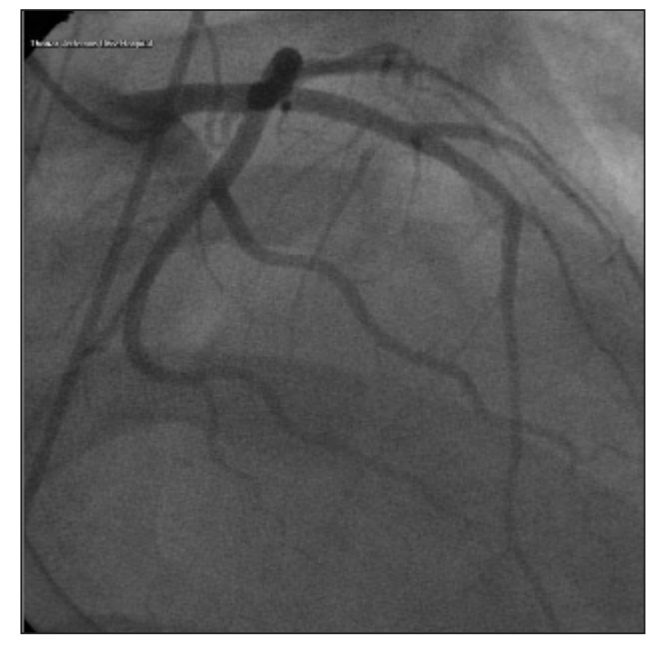

Figure 3.

\section{References}

1. Suhr H. Hambrecht S. Mauser M. Fleischmann D. Foesel T. [Blunt chest trauma with severe pulmonary contusion and traumatic myocardial infarction]. [German] Anasthesiologie, Intensivmedizin, Notfallmedizin, Schmerztherapie 2000; 35(11):717-20.

2. Rohe G. Feyerherd F. Mox B. Hachenberg T. [Acute traumatic myocardial infarction with cardiogenic shock in severe polytrauma--a case report]. [German] Anasthesiologie, Intensivmedizin, Notfallmedizin, Schmerztherapie 2000; 35(4):262-5

3. Grossfeld PD. Friedman DB. Levine BD. Traumatic myocardial infarction during competitive volleyball: a case report. Medicine \& Science in Sports \& Exercise 1993; 25(8):901-3. 